\title{
EHEC
}

\section{Wann sollten Antibiotika eingesetzt werden?}

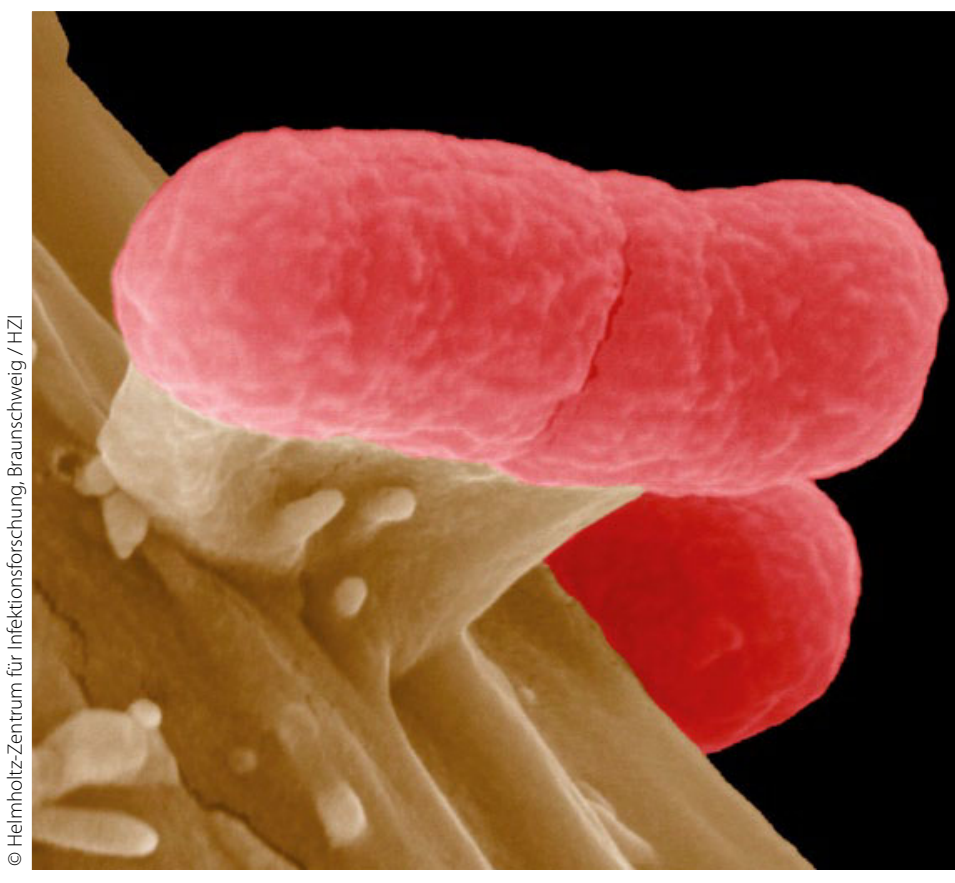

Enterohämorrhagischer E. coli auf einer Darmzelle.
Antibiotika (gegen Coli-Bakterien wirken am besten Gyrasehemmer) sollte man nur im Extremfall geben, wenn der Keim schon nachgewiesen und der Krankheitsverlauf schon sehr weit fortgeschritten ist, sagte Prof. Dr. U. R. Fölsch, Kiel, in unserem Interview zum Thema EHEC (MMW Nr. 22/2011 S. 7). Dazu ein Leser:

— Zu EHEC und dem Interview mit Prof. Fölsch möchte ich einige Anmerkungen machen. Der am besten gegen Coli-Bakterien wirksame Gyrasehemmer ist zweifellos das Fluorchinolon Ciprofloxacin. Meiner Meinung nach sollte Ciprofloxacin so früh wie möglich gegeben werden, $d$. h. wenn die ersten eindeutigen Symptome vorliegen oder nach dem Schnelltest der Keim nachgewiesen ist. Wenn der Krankheitsverlauf weit fortgeschritten ist, z. B. im HUS-Stadium, verbietet sich die Anwendung des Antibiotikums von selbst. Die spontane Freisetzung der Toxine aus den abgetöteten Bakterien würde dann den Krankheitsverlauf sicher zusätzlich negativ beeinflussen.

- Prof. Dr. Klaus Grohe per E-Mail

Leserumfrage Wie steht es um die privaten Honorare?

\begin{abstract}
- Wie ist der aktuelle Stand der Privatmedizin? Wie sieht die Zahlungsmoral der Patienten aus, und wie lässt sie sich steuern? In welche Richtung hat sich die Honorarsituation bei Leistungen für Privatpatienten und bei IGeL weiter entwickelt? Diese Fragen wollen die Fachverlagsgruppe SpringerMedizin und die PVS/Die Privatärztlichen VerrechnungsStellen mit Hilfe einer gemeinsamen Leserumfrage beantworten, die Mitte Juni gestartet ist.
\end{abstract}

Auch Leser der MMW können sich noch bis zum 3. Juli (Einsendeschluss) beteiligen.

Der Fragebogen ist abrufbar unter www.aerztezeitung.de/privathonorare

Die Umfrage ist zusätzlich als Werkzeug für den Praxisvergleich gedacht: Leser, die einen individuellen Abgleich ihrer Daten aus der Umfrage mit denen von Kollegen wünschen - etwa zum durchschnittlichen Rechnungsbetrag können ihre persönlichen Daten über-

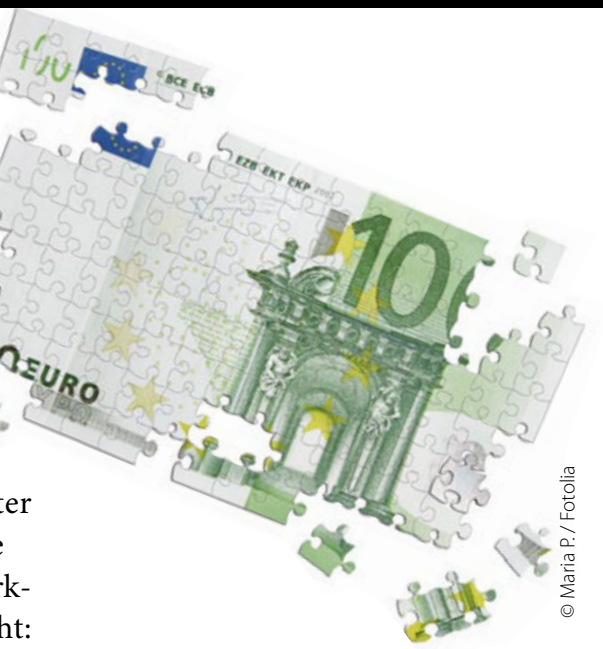

mitteln. Sie erhalten die Benchmarking-Analyse dann direkt von der PVS. Wer kein Benchmarking möchte, kann anonym an der Umfrage teilnehmen. 